RESEÑAS

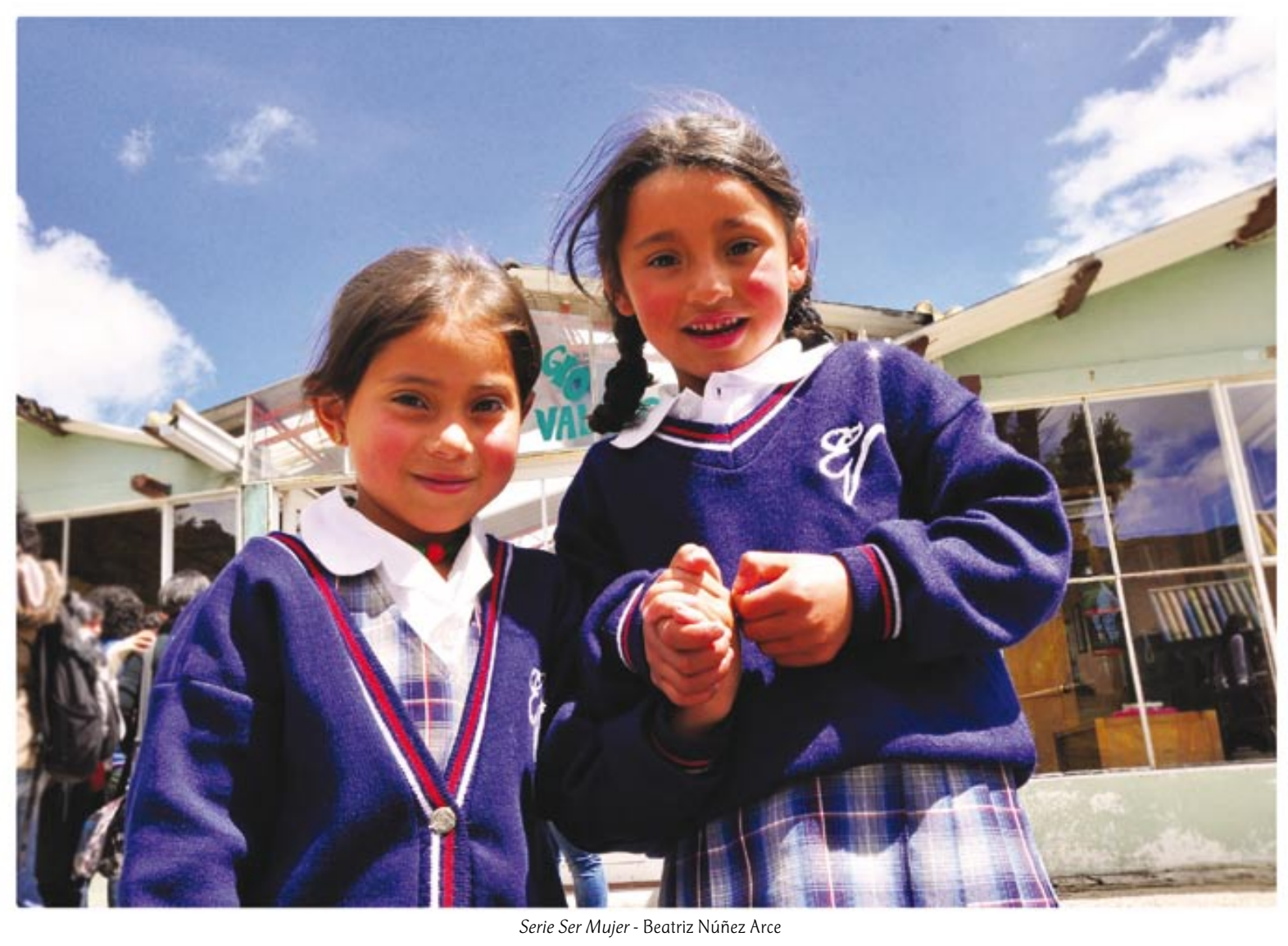




\title{
Biodesarrollo y economía campesina. Aportes para el estudio de la agroindustria panelera en Colombia
}

\author{
Biodevelopment and peasant economy. \\ Contributions to the study of the agro-industry of jaggery in Colombia
}

Óscar Useche Aldana. Edición colombiana: Editorial Corporación Universitaria Minuto de Dios. Bogotá, 2011.

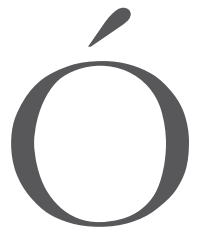

scar Useche Aldana presenta un libro de corte investigativo en el que propone un nuevo enfoque para abordar la economía campesina a partir del biodesarrollo. Usa como marco de contexto el estudio de casos de la producción panelera en los departamentos de Cauca y Tolima, dentro de un conjunto de acontecimientos que han marcado los últimos tiempos a nivel global por medio de la profundización del modelo neoliberal, en el que las grandes multinacionales han articulado la estrategia de los "acuerdos" de libre comercio.

Mientras tanto, a nivel nacional, el tema agrario se convierte en uno de los puntos centrales de la agenda en los diálogos de paz en la Habana. La ley de víctimas y restitución de tierras empieza a implementarse con gran precariedad y, por último, las crecientes protestas de los últimos meses por parte de amplios sectores campesinos. Permitiendo a los académi- cos interesados en el tema agrícola comprender desde un nuevo ángulo los acontecimientos ocurridos.

En el primer capítulo se introducen los elementos esenciales para comprender el biodesarrollo, por medio de una discusión crítica de los impactos económicos del modelo neoliberal sobre la biosfera, al mismo tiempo se explican las relaciones nucleares entre la bio-economía, la bio-política y el biodesarrollo. A continuación muestra en el segundo capítulo las nuevas problemáticas para los productores paneleros en el marco del contexto de globalización y los tratados de libre comercio. El tercer capítulo caracteriza las racionalidades en la producción panelera, sus escalas de producción y las lógicas culturales como diversas y con múltiples potencias que les han permitido superar las dificultades.

En los siguientes tres capítulos se muestran los casos regionales de la producción panelera

1 Aspirante a Magister en Desarrollo Educativo y social de CINDE en convenio con la Universidad Pedagógica de Colombia. Psicólogo comunitario de la Fundación Universitaria Konrand Lorenz. Docente investigador del Centro de Pensamiento Humano y Social, Uniminuto. Correo electrónico: edward.pinzon@gmail.com 
en el Cauca y Tolima, ofreciendo una descripción de los principales problemas para hacer viable y sostenible económicamente este subsector; pasando a realizar un análisis riguroso de la pobreza rural en Colombia, sus indicadores, niveles de inequidad nacional y comparaciones entre los datos del mundo rural y urbano. Abordando el sexto capítulo, un par de propuestas desde las cuales los campesinos pueden participar en los circuitos agroalimentarios regionales. Para cerrar con los últimos dos capítulos, documentando los impactos de la guerra sobre la organización campesina, y las múltiples y creativas estrategias para resistir de forma noviolenta y permanecer en sus territorios.

Para concluir, se puede afirmar que este libro aporta una mirada crítica sobre la economía campesina, en la que se introduce el biodesarollo como un enfoque que desborda el campo de la economía y permite entrar en diálogo con nuevas racionalidades. Esta perspectiva enriquece los análisis convencionales y vislumbra otras salidas a los desafiantes retos que tienen que encarar las nuevas generaciones de colombianos(as). Además, se hacen visibles las experiencias de una multitud de comunidades campesinas que resisten apelando a formas noviolentas en territorios marcados por la guerra. Sin lugar a dudas, este último aporte le da una panorámica más amplia al análisis económico al situarlo dentro de un contexto político y cultural que inevitablemente se cruza en un estudio de esta naturaleza, pero no por esto suelen ser tenidos en cuenta.

El biodesarrollo y la economía campesina nos ofrecen elementos de análisis para reflexionar sobre el momento político que atraviesa este país, solo como ejemplo, vale la pena considerar el papel que puede jugar la academia para dar luces en la implementación de la ley de víctimas y restitución de tierras a cargo del Incoder; según su directora, ya existen recursos para la primera etapa, en la cual se asignarán un millón de hectáreas para las víctimas del conflicto armado. Esto implica un reto mayúsculo que exige el interés y la voluntad política para realizar un trabajo sistemático de investigación de las dinámicas productivas, culturales y políticas del mundo rural. 